\title{
Postdischarge venous thromboembolic complications following pulmonary oncologic resection: An underdetected problem
}

\author{
John Agzarian, MD, MPH, ${ }^{a}$ Waël C. Hanna, MD, MBA, ${ }^{a}$ Laura Schneider, BSc, ${ }^{a}$ Colin Schieman, MD, ${ }^{a}$ \\ Christian J. Finley, MD, MPH, ${ }^{\mathrm{a}}$ Yury Peysakhovich, MD, ${ }^{\mathrm{a}}$ Terri Schnurr, RN, ${ }^{\mathrm{b}}$ Dennis Nguyen-Do, BPH, \\ Lori-Ann Linkins, MD, MSc, ${ }^{b}$ James Douketis, MD, ${ }^{\mathrm{b}}$ Mark Crowther, MD, MSc, ${ }^{\mathrm{b}}$ \\ Marc De Perrot, MD, MSc, ${ }^{c}$ Thomas K. Waddell, MD, PhD, ${ }^{\mathrm{c}}$ and Yaron Shargall, $\mathrm{MD}^{\mathrm{a}}$
}

\begin{abstract}
Objectives: To determine the prevalence of delayed postoperative venous thromboembolism (VTE) in patients undergoing oncologic lung resections, despite adherence to current in-hospital VTE prophylaxis guidelines.

Methods: Patients undergoing lung resection for malignancy in 2 tertiary-care centers were recruited between June 2013 and December 2014. All patients received guideline-based VTE prophylaxis until hospital discharge. Patients underwent computed tomography chest angiography with pulmonary embolism (PE) protocol and bilateral lower extremity venous Doppler ultrasonography at $30 \pm 5$ days after surgery to determine the incidence of postoperative VTE. Univariate analysis was used to compare the VTE and non-VTE groups.
\end{abstract}

Results: A total of 157 patients were included, $45.9 \%$ were men with a mean age of 66.7 years. VTE prevalence was $12.1 \%$ with a total of 19 VTE events, including 14 PEs (8.9\%), 3 deep venous thromboses (DVTs) (1.9\%), 1 combined $\mathrm{PE} / \mathrm{DVT}$, and 1 massive left atrial thrombus originating from the pulmonary vein stump after pulmonary lobectomy. PE events occurred in the operated lung $64 \%$ of the time and 4 patients $(21.1 \%)$ were symptomatic at diagnosis. The 30-day mortality rate of VTE events was $5.2 \%$, with 1 patient who died secondary to massive in situ ipsilateral PE following readmission to the hospital. Univariate analysis did not demonstrate significant differences between the VTE and non-VTE populations with regard to baseline characteristics.

Conclusions: Despite adherence to in-hospital standard prophylaxis guidelines, VTE events are frequent, often asymptomatic, and with associated significant morbidity and mortality. More research into the potential role of predischarge screening and extended prophylaxis is warranted. (J Thorac Cardiovasc Surg 2016;151:992-9)

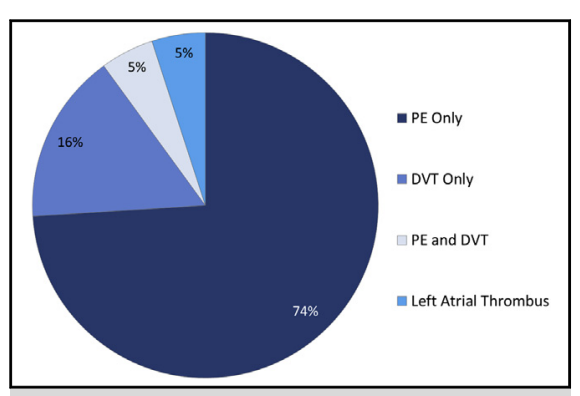

Distribution of venous thromboembolism event types, demonstrating a high proportion of de novo pulmonary embolism (PE).

\section{Central Message}

Despite adoption of in-hospital prophylaxis standards, late VTE after lung cancer resection occurs frequently and is often asymptomatic.

\section{Perspective}

Reported rates of venous thromboembolic events after oncologic lung resection are varied. This is the first prospective study to evaluate prevalence in this population while following current in-hospital prophylaxis guidelines, and notes that prevalence is higher than previously reported and usually asymptomatic at diagnosis. Routine screening or extended postdischarge prophylaxis may be indicated.

See Editorial Commentary page 1000 .
Following pulmonary resection for lung cancer, patients who experience venous thromboembolism (VTE) events, including deep vein thrombosis (DVT) and pulmonary embolism (PE), have a mortality rate as high as $14.3 \%$,

From the ${ }^{\mathrm{a}}$ Departments of Surgery and ${ }^{\mathrm{b}}$ Medicine, McMaster University Faculty of Health Sciences, Hamilton, Ontario, Canada; and ${ }^{\mathrm{c}}$ Department of Surgery, University of Toronto, Faculty of Medicine, University Health Network, Toronto, Ontario, Canada.

Supported by the Heart and Stroke Foundation of Canada (grant No. G-13-0002751). Received for publication April 28, 2015; revisions received Oct 27, 2015; accepted for publication Nov 21, 2015; available ahead of print Dec 19, 2015.

Address for reprints: Yaron Shargall, MD, St Joseph's Healthcare Hamilton,

50 Charlton Ave, E Juravinski Tower T-2105, Hamilton, ON, L8N 4A6 Canada

(E-mail: shargal@mcmaster.ca).

$0022-5223 / \$ 36.00$

Copyright (c) 2016 by The American Association for Thoracic Surgery

http://dx.doi.org/10.1016/j.jtcvs.2015.11.038 compared with a mortality risk of $2 \%$ in uncomplicated cases void of VTE. ${ }^{1}$ The clinical burden of postoperative VTE in thoracic surgery is likely underestimated because the majority of patients are asymptomatic or misdiagnosed. ${ }^{2}$ There is generally little concordance of the reported incidence of VTE after thoracic surgery, with rates ranging from $1.3 \%$ to $15.2 \%$ for PE, and $4 \%$ to $14 \%$ for DVT. ${ }^{1-8}$ Older studies, conducted between 1975 and 1993, before

Scanning this QR code will take you to the article title page. 


\section{Abbreviations and Acronyms \\ CT = computed tomography \\ CTPA = computed tomography pulmonary angiogram \\ DVT = deep venous thrombosis \\ LMHW = Low-molecular-weight heparin \\ $\mathrm{PE}=$ pulmonary embolism \\ UFH = unfractionated heparin \\ VTE = venous thromboembolism}

the routine use of heparin prophylaxis, reported a mortality rate from $\mathrm{PE}$ as high as $15.2 \%$ in the lung cancer population. ${ }^{3,4}$ More recent literature reports the incidence of PE in this population to be $5 \%$, and that of DVT to be $4 \%$ to $14 \%,{ }^{5-8}$ although most of these studies reported only clinically evident events. A contemporary screeningbased study, using spiral helical computed tomography (CT) scanning 7 to 15 days postoperatively, detected both symptomatic and asymptomatic events, and reported a markedly higher incidence of PE at $14 \%{ }^{2}$ while following current VTE prophylaxis guidelines. 9

Pertaining to the thoracic surgery population, the American College of Chest Physicians ninth edition guidelines for VTE prevention recommend the use of in-hospital routine VTE prophylaxis with either low-dose unfractionated heparin (UFH) or low-molecular-weight heparin (LMWH) (Grade 1B), ${ }^{9}$ with no recommendations for continuation after hospital discharge. This is despite an American College of Surgeons National Surgical Quality Improvement Program database review indicating that after lung cancer resection, $23 \%$ of VTE events occur after discharge and another study by Yang and colleagues reported that VTE. ${ }^{1}$ In contrast, for patients undergoing major orthopedic procedures, there is prospective evidence to support long-term prophylaxis up to 35 days ${ }^{10}$ after discharge. ${ }^{11-15}$ These findings have been echoed in abdominal and pelvic cancer surgery, where prospective randomized trials have demonstrated that VTE prophylaxis up to 30 days after surgery results in significantly fewer VTE events. ${ }^{1,16}$

The aim of this multicenter pilot study was to prospectively determine the postoperative prevalence and clinical burden of clinically evident and occult VTE following oncologic lung resection, using delayed screening investigations 30 days postoperatively. We also examine the use of VTE prophylaxis in this population to determine whether current thromboprophylaxis guidelines are being appropriately followed. By assessing symptomatic and subclinical events, we hypothesize that the detected prevalence of VTE will be higher than previously suspected, despite adhering to standard prophylaxis guidelines. As part of a 3-phase project, we aim to use these findings to investigate the role of extended
VTE thromboprophylaxis in the thoracic surgery patient population.

\section{METHODS \\ Patient Selection}

Between June 2013 and December 2014, patients undergoing lung resection for primary or secondary lung malignancies in 2 tertiary-care centers (St Joseph's Healthcare Hamilton, Hamilton, ON, Canada, and Toronto General Hospital, Toronto, ON, Canada) were recruited to participate in this prospective cohort study. Adults aged 18 years or older undergoing open or minimally invasive lobar or sublobar resection (eg, wedge resection, segmentectomy, lobectomy, bilobectomy, or pneumonectomy) were considered for enrollment. Patients were excluded if they had a known allergy to contrast dye, UFH, or LMWH; were at an increased risk of hemorrhage; had a history of heparin-induced thrombocytopenia; had known renal impairment (defined as creatinine clearance $<55 \mathrm{~mL} / \mathrm{min} / \mathrm{m}^{2}$ as calculated by the Cockroft-Gault method); had a platelet count $<75,000$; or were pregnant. Patients were deemed ineligible if they demonstrated any history of prior VTE during the 3 months before surgery, had previous inferior vena cava filter insertion, and/or were concurrently on therapeutic anticoagulation. The study was approved by the Hamilton Integrated Research Ethics Board and University Health Network Research Ethics Board before patient enrollment.

\section{VTE Prophylaxis Management}

Each study subject received American College of Chest Physicians guideline-compatible thromboprophylaxis consisting of mechanical prophylaxis via graduated compression stockings, along with chemical prophylaxis consisting of either subcutaneous injection of 5000 units dalteparin once daily, or 5000 units UFH every 8 hours. The initial dose of chemical prophylaxis was administered intraoperatively within 2 hours of the beginning of each operation, defined as the time at which the initial skin incision was made, in accordance with hospital and anesthesia-specific guidelines for perioperative DVT prophylaxis. For patients with thoracic epidurals, catheter removal was coordinated with the last administered dose of chemical thromboprophylaxis according to hospital-specific nursing guidelines. In the case of dalteparin, the epidural catheter was removed at least 2 hours before administration of the next dose, after checking patient international normalized ratio and partial thromboplastin time. Specific to UFH, epidural catheters were typically removed in the morning after holding the first dose of heparin. The regimen of UFH was then resumed 2 hours after catheter removal. Prophylaxis continued only until hospital discharge. All patients were ambulated on the first postoperative day and daily thereafter by a physiotherapist.

\section{Outcomes Measurement}

Each study participant was scheduled for 2 early postoperative outpatient follow-up visits. Patients were initially seen 2 weeks postoperatively for a clinical assessment of symptoms suggestive of VTE. This clinical assessment was repeated 4 weeks postoperatively, followed by objective radiographic screening for PE and DVT, often on the same visit date. All participants underwent a chest CT pulmonary angiogram (CTPA) with contrast using a 64-slice multidetector CT (Lightspeed CT; GE Healthcare Milwaukee, Wis) and bilateral aboveknee lower extremity venous Doppler ultrasonography at $30 \pm 5$ days after surgery. Before undergoing CTPA examination, all patients provided blood samples to rule out significant postoperative bleeding and/or the development of postprocedural renal impairment. Patients who developed symptoms suggestive of VTE events before the 30-day mark, either during hospitalization or during outpatient clinical follow-up, underwent an urgent CTPA examination based on the clinical judgment of the treating surgeon. 
For those participants, a subsequent scan was still completed at 30-days postoperatively if the initial study was negative. Radiographic diagnostic criteria for PE consisted of an abrupt cutoff of segmental or subsegmental arterial vessels, a partial central vascular filling defect, or a partial eccentric vascular filling defect seen on CT. The presence of VTE was confirmed by 2 independent radiologists. Patients found to have VTE were seen by their thoracic surgeon within 1 to 3 days after diagnostic confirmation, and were referred immediately to the thrombosis service for treatment. Patients with VTE events were placed on appropriate anticoagulation and were followed by the thrombosis team to determine treatment duration and extent. Patient demographic characteristics, comorbidities, pathologic cancer stage, operative details, postoperative complications, and VTE-related outcomes were recorded up to 3 months after surgery. Patient risk for developing VTE was calculated using the Caprini VTE risk stratification score, a validated composite score known to correlate to each patient's risk of developing a VTE postoperatively. ${ }^{17}$

\section{Statistical Analysis}

All data were collected prospectively and analyzed using the SPSS statistical software program (version 20.0 for Windows; IBM-SPSS Inc, Armonk, NY). Binary data were reported as proportions, and continuous data were reported using means and standard deviation or medians with full range. Univariate analysis was used to compare the VTE and non-VTE groups to ascertain any distinguishing features between groups. Categorical data were analyzed using the Fisher exact test for binomial proportions, and continuous data were analyzed using the Student $t$ test.

\section{RESULTS \\ Patient Characteristics}

A total of 174 patients were enrolled for participation, with $157(90.2 \%)$ completing follow-up investigations necessary for inclusion in this analysis (Figure 1). As described in Table 1, the study cohort consisted of $45.9 \%$ men, with a mean age of 66.6 years. Approximately $78 \%$ of study participants had primary lung cancer. The majority of patients underwent anatomic resection $(65.0 \%$ lobectomy, $17.2 \%$ segmentectomy, and $3.8 \%$ pneumonectomy) with only $12.7 \%$ undergoing wedge resections. Thoracoscopic resection was performed in $54 \%$ of patients, with the remaining procedures completed via thoracotomy $(42.4 \%)$ or robotically $(3.8 \%)$. Based on a corresponding Caprini score $>5,{ }^{17} 81.8 \%$ of participants were at high risk for the development of VTE. Median length of the stay was 5 days, with a range of 1 to 24 days. When considering the distribution of patient and surgical characteristics of those patients who experienced VTEs, there were no statistically significant differences (Table 1).

Table 2 summarizes the univariate comparative analysis of intra- and postoperative complication rates of patients

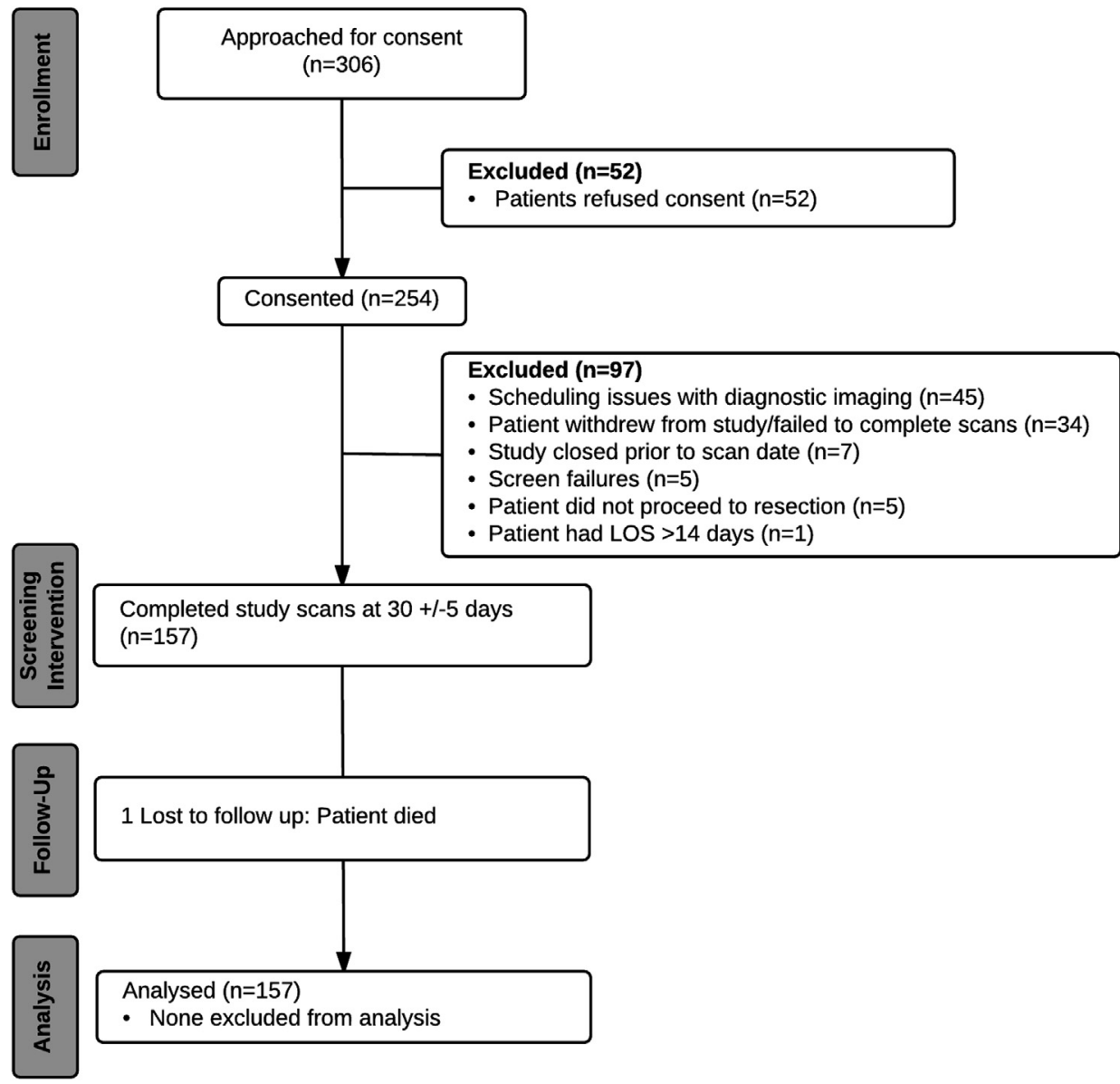

FIGURE 1. Consolidated standards of reporting trials diagram of study patient flow. LOS, Length of stay. 
TABLE 1. Cohort patient demographic characteristics and surgical technique summary with distribution of characteristics across venous thromboembolism (VTE) event occurrence

\begin{tabular}{|c|c|c|c|c|}
\hline Patient attribute & $\begin{array}{l}\text { Cohort frequency } \\
\quad(n=157)\end{array}$ & $\begin{array}{c}\text { Frequency in subcohort } \\
\text { with no VTE events }(n=138)\end{array}$ & $\begin{array}{l}\text { Frequency in subcohort with } \\
\text { VTE event subcohort }(n=19)\end{array}$ & $P$ value \\
\hline Age (y) & $66.55 \pm 9.24$ & $66.25 \pm 8.88$ & $69.05 \pm 11.51$ & .216 \\
\hline Men & $72(45.9)$ & $62(86.1)$ & $10(13.9)$ & .626 \\
\hline$\%$ Predicted FEV1 & $73.51(33.02)$ & $72.34(32.68)$ & $82.50(35.11)$ & .220 \\
\hline$\%$ Predicted DLCO & $71.48(19.33)$ & $72.07(19.88)$ & $67.0(14.13)$ & .326 \\
\hline Charlson Comorbidity Index & $2.22 \pm 2.08$ & $2.19 \pm 2.07$ & $2.42 \pm 2.24$ & .649 \\
\hline Length of stay (d) & $5(1-24)$ & $6(3-24)$ & $5(1-15)$ & .185 \\
\hline Caprini score* & & & & .530 \\
\hline High risk & $29(18.5)$ & $27(93.1)$ & $2(6.9)$ & \\
\hline Highest risk & $128(81.5)$ & $111(86.7)$ & $17(13.3)$ & \\
\hline Smoking status & & & & .441 \\
\hline Never smoker & $31(19.7)$ & $26(83.9)$ & $5(16.1)$ & \\
\hline Former smoker & $87(55.4)$ & $79(90.8)$ & $8(9.2)$ & \\
\hline Current smoker & $38(24.2)$ & $32(84.2)$ & $6(15.8)$ & \\
\hline Tumor pathology & & & & .513 \\
\hline T1a & $33(26.0)$ & $27(81.8)$ & $6(18.2)$ & \\
\hline T1b & $21(16.5)$ & 18 (85.7) & $3(14.3)$ & \\
\hline $\mathrm{T} 2 \mathrm{a}$ & $42(33.1)$ & $35(83.3)$ & $7(16.7)$ & \\
\hline $\mathrm{T} 2 \mathrm{~b}$ & $12(9.4)$ & $11(91.7)$ & $1(8.3)$ & \\
\hline $\mathrm{T} 3$ & $16(12.6)$ & $16(100)$ & 0.0 & \\
\hline $\mathrm{T} 4$ & $3(2.4)$ & $3(100)$ & 0.0 & \\
\hline Lymph node pathology & & & & .566 \\
\hline $\mathrm{NX}$ & $4(3.1)$ & $4(100)$ & 0.0 & \\
\hline No & $92(72.4)$ & 79 (85.9) & $13(14.1)$ & \\
\hline N1 & $23(18.1)$ & $21(91.3)$ & $2(8.7)$ & \\
\hline N2 & $8(6.3)$ & $6(0.8)$ & $2(0.2)$ & \\
\hline Lung cancer stage & & & & .901 \\
\hline IA & $44(35.2)$ & $37(84.1)$ & $7(15.9)$ & \\
\hline IB & 37 (29.6) & $31(83.8)$ & $6(16.2)$ & \\
\hline IIA & $15(12.0)$ & $14(93.3)$ & $1(6.7)$ & \\
\hline IIB & $8(6.4)$ & $7(87.5)$ & $1(12.5)$ & \\
\hline IIIA & $18(14.4)$ & $16(88.9)$ & $2(11.1)$ & \\
\hline IIIB & $3(2.4)$ & $3(100)$ & 0.0 & \\
\hline Histology & & & & .926 \\
\hline Squamous cell carcinoma & $33(21.1)$ & $29(87.9)$ & $4(12.1)$ & \\
\hline Adenocarcinoma & $73(46.8)$ & $63(86.3)$ & $10(13.7)$ & \\
\hline Carcinoid & $12(7.7)$ & $10(83.3)$ & $2(16.7)$ & \\
\hline Mixed subtypes & $5(3.2)$ & $5(100)$ & 0.0 & \\
\hline Metastatic tumors & $23(14.7)$ & $21(91.3)$ & $2(8.7)$ & \\
\hline Surgical procedure & & & & .455 \\
\hline Pneumonectomy & $6(3.8)$ & $6(100)$ & 0.0 & \\
\hline Bilobectomy & $2(1.3)$ & $2(100)$ & 0.0 & \\
\hline Lobectomy & $102(65.0)$ & $87(85.3)$ & $15(14.7)$ & \\
\hline Segmentectomy & $27(17.2)$ & $23(85.2)$ & $4(14.8)$ & \\
\hline Multiple wedge & $8(5.1)$ & $8(100)$ & 0.0 & \\
\hline Single wedge & $12(7.6)$ & $12(100)$ & 0.0 & \\
\hline Surgical approach & & & & .199 \\
\hline VATS right side & $55(35.0)$ & $49(89.1)$ & $6(10.9)$ & \\
\hline VATS left side & $30(19.1)$ & $27(90.0)$ & $3(10.0)$ & \\
\hline Thoracotomy right side & $33(21.0)$ & $31(93.9)$ & $2(6.1)$ & \\
\hline Thoracotomy left side & $32(20.4)$ & $24(75.0)$ & $8(25.0)$ & \\
\hline Robotic & $6(3.8)$ & $6(100)$ & 0.0 & \\
\hline
\end{tabular}

Values are presented as $\mathrm{n}(\%)$, mean \pm standard deviation, or median (range). VTE, Venous thromboembolism; FEVI, forced expiratory volume in 1 second; DLCO, diffusing capacity of the lungs for carbon monoxide; VATS, video-assisted thoracoscopic surgery. ${ }^{*}$ High risk $=3$ or 4 , highest risk $=5+$. 
TABLE 2. Cohort intraoperative and postoperative complication frequency summary during index admission, with distribution of adverse events in subcohorts with and without venous thromboembolism (VTE) events

\begin{tabular}{|c|c|c|c|c|}
\hline Complication & Count $(\%)$ & $\begin{array}{c}\text { Frequency in non-VTE } \\
\text { events }(n=138)\end{array}$ & $\begin{array}{c}\text { Frequency in VTE } \\
\text { events }(n=19)\end{array}$ & $P$ value \\
\hline Intraoperative complications & & & & .085 \\
\hline None & $145(92.4)$ & $129(89.0)$ & $16(11.0)$ & \\
\hline Cerebrovascular accident & $1(0.6)$ & $1(100)$ & $0(0)$ & \\
\hline Clinical bleeding & $2(1.3)$ & $2(100)$ & $0(0)$ & \\
\hline Bleeding requiring transfusion & $2(1.3)$ & $1(50.0)$ & $1(50.0)$ & \\
\hline Vascular injury & $3(1.9)$ & $1(33.3)$ & $2(66.7)$ & \\
\hline Airway injury & $3(1.9)$ & $3(100)$ & $0(0)$ & \\
\hline Esophageal injury & $1(0.6)$ & $1(100)$ & $0(0)$ & \\
\hline Death & $0(0)$ & $0(0)$ & $0(0)$ & \\
\hline \multicolumn{5}{|l|}{ Postoperative complications } \\
\hline None & $86(54.8)$ & $77(89.5)$ & $9(10.5)$ & .624 \\
\hline Any postoperative complication & $71(45.2)$ & $61(85.9)$ & $10(14.1)$ & \\
\hline Atelectasis requiring bronchoscopy & $6(3.8)$ & $5(83.3)$ & $1(16.7)$ & \\
\hline Pneumonia & $8(5.3)$ & $5(62.5)$ & $3(37.5)$ & \\
\hline Pleural effusion & $3(1.9)$ & $3(100)$ & $0(0)$ & \\
\hline Postoperative airleak ( $\geq 7 \mathrm{~d})$ & $18(11.3)$ & $17(94.4)$ & $1(5.6)$ & \\
\hline Subcutaneous emphysema & $13(8.2)$ & $12(92.3)$ & $1(7.7)$ & \\
\hline Atrial fibrillation & $9(5.7)$ & $6(66.7)$ & $3(33.3)$ & \\
\hline Cardiac ischemia & $3(1.9)$ & $2(66.7)$ & $1(33.3)$ & \\
\hline Urinary tract infection & $4(2.5)$ & $4(100)$ & $0(0)$ & \\
\hline Urinary retention & $7(4.4)$ & $5(71.4)$ & $2(28.6)$ & \\
\hline Confusion & $5(3.1)$ & $2(40.0)$ & $3(60.0)$ & \\
\hline Respiratory failure & $2(1.3)$ & $2(100)$ & $0(0)$ & \\
\hline
\end{tabular}

Frequency values are presented as n (\%). VTE, Venous thromboembolism.

with versus without VTE. No significant differences between the 2 groups were found. The most common postoperative complications included prolonged air-leak of $>7$ days' duration $(11.3 \%)$, subcutaneous emphysema $(8.2 \%)$, atrial fibrillation $(5.7 \%)$, pneumonia requiring administration of antibiotics $(5.3 \%)$, and urinary retention $(4.4 \%)$. No intraoperative or in-hospital deaths occurred during the index admission. With regard to in-hospital thromboprophylaxis, $96.2 \%$ of patients (151 out of 157) received intraoperative chemical prophylaxis, with $19.7 \%$ and $80.3 \%$ of patients receiving LMWH and UFH, respectively. Postoperatively, all study participants received chemical prophylaxis: $29.5 \%$ receiving $\mathrm{LMWH}$, and $70.5 \%$ receiving UFH. All patients received intraoperative and postoperative mechanical compression devices. However, data pertaining to mechanical thromboprophylaxis was not collected prospectively to report patient adherence.

\section{VTE Prevalence}

A total of 19 VTE events were reported, corresponding to an overall prevalence of $12.1 \%$ over the 30-day postoperative follow-up period. No clinically apparent events occurred during the index hospital admission. Thrombotic events included 14 PE (8.9\%), 3 DVT (1.9\%), 1 combined PE/DVT $(0.64 \%)$, and 1 massive left atrial thrombus originating from the pulmonary vein stump after lobectomy (Figure 2). PE events demonstrated an ipsilateral predilection, with $63.2 \%$ occurring in the lung that underwent operation. Four PEs $(28.6 \%)$ were arterial stump thrombi at the vascular margin of the resected lung. Among those who experienced thrombotic events, $37.5 \%$ were administered LMWH postoperatively, whereas $62.5 \%$ received UFH. The number of events was too small to allow stratified analysis comparing the rates of VTE based on the type of chemical prophylaxis. All patients diagnosed with VTE had anatomic resections (lobectomy or segmentectomy). Seventeen patients had primary lung cancer and the

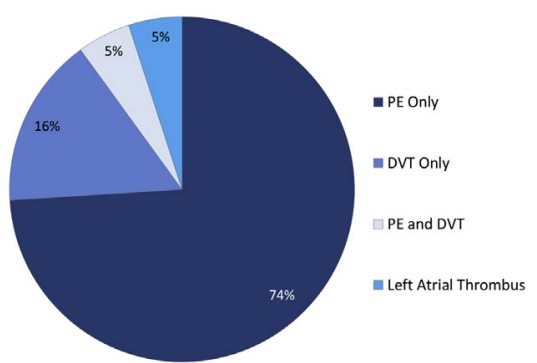

FIGURE 2. Distribution of venous thromboembolism event types, demonstrating a high proportion of de novo pulmonary embolism $(P E)$. $D V T$, Deep venous thrombosis. 
remaining 2 patients had lung metastases and primary lung lymphoma, respectively.

The majority of patients with VTE had isolated PE without an antecedent DVT. Among those with diagnosed VTE, only 4 patients $(21.1 \%)$ were symptomatic at diagnosis. The symptomatic nature of their presentation was only reported post hoc following their CTPA. As such, no comment can be made as to the exact timing of their presentation. One patient died secondary to massive in situ ipsilateral PE, for an overall 30-day mortality of $0.64 \%$. However, among patients who experienced a VTE event, the mortality rate was $5.2 \%$ (1 out of 19 ).

\section{DISCUSSION}

VTE remains a major source of postoperative morbidity and mortality following oncologic surgery, and is of particular clinical significance in the thoracic surgery population. Much of the ambiguity regarding the specific incidence and prevalence of VTE after thoracic surgery is due to the lack of specific symptomatology that can differentiate VTE from expected postsurgical symptoms. As the first prospective evaluation of its kind, this study demonstrates the increased prevalence and associated clinical ramifications of postoperative VTE following lung resection, despite adherence to contemporary recommendations for in-hospital prophylaxis. Notably, among the cohort of 157 patients undergoing resection for primary and secondary lung cancer, the incidence of postoperative VTE was $12.1 \%$, with the majority of cases being asymptomatic, with $\mathrm{PE}$ occurring in the ipsilateral lung in two-thirds of patients. Approximately one-quarter of these were stump thrombi. Postoperative outcomes and complications were generally comparable to accepted norms within the literature. Finally, all VTE events were diagnosed postdischarge, with 1 death in a patient with a massive in situ ipsilateral PE. Despite the overall low mortality, the VTE-specific mortality rate of $5.3 \%$ demonstrates the clinical importance and relative fatality of VTE following lung cancer surgery. The results of this study indicate a need to conduct further research into the potential role of extending VTE prophylaxis up to 30 days postresection among patients undergoing lung cancer surgery.

In the most comprehensive systematic review of the incidence of VTE following lung cancer surgery, including 19 trials and 10,660 patients, the reported incidence was substantially lower than that reported in this study, at $2.0 \%{ }^{18}$ Although our results demonstrate a VTE prevalence that is generally higher than what is reported in the quoted literature, the findings are supported by more recent research attempting to quantify the burden and clinical relevance of VTE following lung resection. In a recent retrospective analysis of 112 patients undergoing lung resection between 2006 and 2012, Raja and colleagues ${ }^{19}$ reported a lower-extremity VTE incidence of $17.9 \%$ following pneumonectomy, with a 3 -fold greater proportion of VTE events being diagnosed in patients who were preemptively screened for VTE compared with those who were investigated only after the development of symptoms. This finding is supported by our study, where nearly $80 \%$ of VTE events were asymptomatic, noted only on screening investigations, and would have otherwise gone undiagnosed and untreated. It is important to note that the Raja and colleagues report ${ }^{19}$ only assessed the rates of DVT in a high-risk postpneumonectomy population, whereas the cohort described in our study considered all lung resection types and reported a greater proportion of de novo PE events to DVT events. It is interesting to note that our reported postoperative DVT rate of $1.9 \%$ is markedly lower than that reported in many published series, even when assessing symptomatic DVT. ${ }^{1,18}$ This finding is difficult to explain given that all patients underwent above-knee duplex ultrasonography, and that results were confirmed by 2 independent radiologists. This could possibly be the result of sampling error given small sample size. Alternatively, some of the reported PEs could have been preceded by DVT that had resolved by the time the Doppler ultrasound was performed.

In another study by Hachey and colleagues ${ }^{20}$ focusing on validating the Caprini postoperative VTE risk score in 232 patients undergoing surgery for lung cancer, the overall 60-day incidence of VTE was reported to be $5.2 \%$, with $50 \%$ of thrombotic events being PE events. However, substratification based on risk profile demonstrated that patients in the highest risk group had an overall incidence of $10.4 \%$. More than $80 \%$ of the patients in our cohort had Caprini scores corresponding to the highest risk category (score $\geq 5$ ), ${ }^{21}$ which could justify the reported higher prevalence rate. The Hachey and colleagues cohort study $^{20}$ was a retrospective chart review from 2005 to 2013, and as such, all reported cases were diagnosed secondary to symptoms, potentially explaining the overall lower VTE incidence. Additionally, Hachey and colleagues $^{20}$ reported that $92 \%$ of VTE occurred in postthoracotomy patients, whereas our cohort consisted of $47 \%$ incident cases following video-assisted thoracoscopic surgery, and so the results of Hachey and colleagues ${ }^{20}$ may not be comparable to institutions with a much greater proportion of minimally invasive cases.

Several factors may increase the thromboembolic risk in cancer patients undergoing lung resection, as well as their potential clinical consequences. These include general factors, such as the intrinsic procoagulant effect of cancer, extensive surgical intervention, and dependent limb position in the operating room. ${ }^{5}$ Furthermore, local factors related to surgical technique and direct pulmonary vascular injury, including the manipulation of the pulmonary arteries and division/ligation of arterial branches, may potentially 
play an important role in formation of in situ thrombi even without antecedent DVT. ${ }^{2}$ This was demonstrated in this study, with $74 \%$ of PE events occurring independent of existing DVT, potentially indicating the unique risk of direct injury to the lung-moderating event rates in this population. It also highlights the fact that patients undergoing lung surgery might altogether have a different VTE profile than that of general oncology and orthopedic surgery patients, with a higher rate of de novo PE (nonvenous) events, in which case DVT screening alone might miss a substantial proportion of thrombotic events.

It is unclear whether in situ thrombi in an arterial stump carry significant risks to patients. Numerous reports have indicated that the propagation of large clots at the stumps of resected vessels may have resulted in subsequent massive PE. ${ }^{22-26}$ The local effects and surgical manipulation of the lung and its associated vasculature might lead to an intensified risk of developing VTE, a concept that is supported by the results of our report. An enhanced effect on morbidity and mortality after lung cancer resection surgery can be attributed to the compromised lung function experienced by these patients after removal of significant portions of the lung. The resultant effect may be that the development of PE following lung resection can be more fatal than in the general population.

A recent study by our research team ${ }^{27}$ evaluated Ontario's population-based database from 2005 to 2011 and demonstrated that patients undergoing lobectomy and pneumonectomy had increased postdischarge mortality up to 90 days postsurgery. Patients undergoing lobectomy had $1.4 \%$ in-hospital mortality, and $1.9 \%$ additional mortality postdischarge. Patients undergoing pneumonectomy had $4.6 \%$ in-hospital mortality, but an additional $6.4 \%$ mortality postdischarge. ${ }^{28}$ These findings may indicate the potential contribution of VTE to postdischarge mortality after major lung resections for malignancy.

The strengths of this study include the prospective analysis and data retrieval, as well as having a cohort of patients larger than other recent research involving this particular surgical population. All recruited patients, regardless of clinical symptoms, underwent screening for VTE at 30 days after surgery, hence enhancing the generalizability of the results. Furthermore, the standardized and prolonged follow-up of study participants provides a thorough and comprehensive analysis of outcomes. Several limitations exist that potentially compromise the validity of the reported findings. Because it is a pilot study, the sample size of 157 patients has diminished statistical power, and limits the inference of comparative analyses. Nonetheless, this remains the largest prospective cohort of patients in the literature to-date investigating VTE rates after surgery for lung cancer. Another limitation lies in the fact that study participants did not undergo CTPA or venous Doppler ultrasonography screening investigations before surgical resection to rule out the presence of preoperative VTE. The influence of this design limitation is likely small, because all patients underwent contrastenhanced CT examination of the chest as part of preoperative staging, and although not specifically designated for the evaluation of $\mathrm{PE}$, none of the investigations demonstrated any overt filling defects to suggest the possibility of PE. Finally, although the median length of stay was comparable between the VTE and non-VTE groups, it is difficult to ascertain the effects of longer in-hospital prophylaxis on the development of VTE for patients with a prolonged hospital length of stay. This question should be addressed in a planned randomized controlled trial investigating the role of extended VTE prophylaxis in patients undergoing resection for lung cancer.

\section{CONCLUSIONS}

The prevalence of VTE after lung resection is significant despite the current standard of care for in-hospital VTE prophylaxis. The majority of VTE events were asymptomatic, and all were noted in the postdischarge time frame. This indicates a need to consider the role of pre- or postdischarge VTE screening and extended out-of-hospital VTE prophylaxis after lung cancer resection. At the current time, our VTE prophylaxis guidelines indicate in-hospital-only prophylaxis. We have recently started a prospective, randomized placebocontrolled study comparing extended postdischarge prophylaxis to postdischarge placebo. The results of that study will help to further evaluate the role of extended VTE prophylaxis in thoracic surgery.

\section{Conflict of Interest Statement}

Dr Shargall reports grants from Heart and Stroke Foundation of Canada during the conduct of the study. Dr Linkins reports grants and personal fees from Bayer and personal fees from Pfizer outside the submitted work. Dr Crowther reports grants from Pfizer, BSM-Pfizer alliance, Leo, Sanofi, Bayer, BI, Octapharma, CSL Behring, Portola, and personal fees from Pfizer, BSM-Pfizer alliance, Leo, Sanofi, Bayer, BI, Octapharma, CSL Behring, and Portola outside the submitted work. All other authors have nothing to disclose with regard to commercial support.

\footnotetext{
References

1. Merkow RP, Bilimoria KY, McCarter MD, Cohen ME, Barnett CC, Raval MV, et al. Post-discharge venous thromboembolism after cancer surgery. Extending the case for extended prophylaxis. Ann Surg. 2011;254:131-7.

2. Daddi G, Milillo G, Lupattelli L, Ragusa M, Lemmi A, Puma F, et al. Postoperative pulmonary embolism detected with multislice computed tomography in lung surgery for cancer. J Thorac Cardiovasc Surg. 2006;132: 197-8.

3. Azorin JF, Regnard JF, Dahan M, Pansart M. Efficacy and tolerability of Fraxiparine in the prevention of thromboembolic events in lung cancer. Ann Cardiol Angeiol. 1997;46:341-7.
} 
4. Cade JF, Clegg EA, Westlake GW. Prophylaxis of venous thrombosis after major thoracic surgery. Aust N Z J Surg. 1983;53:301-4.

5. Dentali F, Malato A, Ageno W, Imperatori A, Cajozzo M, Rotolo N, et al. Incidence of venous thromboembolism in patients undergoing thoracotomy for lung cancer. J Thorac Cardiovasc Surg. 2008;135:705-6.

6. Kalweit G, Huwer H, Volkmer I, Petzold T, Gams E. Pulmonary embolism: a frequent cause of acute fatality after lung resection. Eur J Cardiothorac Surg. 1996; 10:242-6.

7. Ziomek S, Read RC, Tobler HG, Harrell JE Jr, Gocio JC, Fink LM, et al. Thromboembolism in patients undergoing thoracotomy. Ann Thorac Surg. 1993:56:223-6.

8. Saarinen J, Kallio T, Sisto T, Tarkka M. Incidence of deep venous thrombosis after thoracotomy. Vasa. 2001;30:259-61.

9. Gould MK, Garcia DA, Wren SM, Karanicolas PJ, Arcelus JI, Heit JA, et al. Prevention of VTE in nonorthopedic surgical patients: antithrombotic therapy and prevention of thrombosis, 9th ed: American College of Chest Physicians Evidence-Based Clinical Practice Guidelines. Chest. 2012;141(Suppl): e227S-77S.

10. Falck-Ytter Y, Francis CW, Johanson NA, Curley C, Dahl OE, Schulman S, et al. Prevention of VTE in orthopedic surgery patients: antithrombotic therapy and prevention of thrombosis, 9th ed: American College of Chest Physicians EvidenceBased Clinical Practice Guidelines. Chest. 2012;141(Suppl):e278S-325S.

11. Bergqvist D, Angelli G, Cohen AT, Eldor A, Nilsson PE, Le Moigne-Amrani A, et al. Duration of prophylaxis against venous thromboembolism with enoxaparin after surgery for cancer. $N$ Engl J Med. 2002;346:975-80.

12. Planes A, Vochelle N, Darmon JY, Fagola M, Bellaud M, Huet Y. Risk of deep-venous thrombosis after hospital discharge in patients having undergone total hip replacement: double-blind randomised comparison of enoxaparin versus placebo. Lancet. 1996;348:224-8.

13. Dahl OE, Andreassen G, Aspelin T, Müller C, Mathiesen P, Nyhus S, et al. Prolonged thromboprophylaxis following hip replacement surgery-results of a double-blind, prospective, randomised, placebo-controlled study with dalteparin (Fragmin). Thromb Haemost. 1997;77:26-31.

14. Lassen MR, Borris LC, Anderson BS, Jensen HP, Skejø Bro HP, Andersen G, et al. Efficacy and safety of prolonged thromboprophylaxis with a low molecular weight heparin (dalteparin) after total hip arthroplasty-the Danish Prolonged Prophylaxis (DaPP) study. Thromb Res. 1998;89:281-7.

15. Hull RD, Pineo GF, Francis C, Bergqvist D, Fellenius C, Soderberg K, et al. Low-molecular-weight heparin prophylaxis using dalteparin extended out-of-hospital vs. in-hospital warfarin/out-of-hospital placebo in hip arthroplasty patients: a double-blind randomized comparison. Arch Intern Med. 2000;160:2208-15.

16. Kakkar VV, Balibrea JL, Martinez-Gonzalez J, Prandoni P. CANBESURE study group. Extended prophylaxis with bemiparin for the prevention of venous thromboembolism after abdominal or pelvic surgery for cancer: the CANBESURE randomized study. J Thrombos Haemostas. 2010;8:1223-9.

17. Caprini JA, Arcelus J, Hast JH, Tamhane AC, Fabrega F. Clinical assessment of venous thromboembolic risk in surgical patients. Semin Thrombo Herrost. 1991 17(Suppl 3):304-12.

18. Christensen T, Vad H, Pedersen S, Hvas AM, Wotton R, Naidu B, et al Venous thromboembolism in patients undergoing operations for lung cancer: a systematic review. Ann Thorac Surg. 2014;97:394-401.

19. Raja S. Routine VTE screening after pneumonectomy: you must look to find Paper presented at: the 95th Annual Meeting of the American Association for Thoracic Surgery; April 25-29, 2015; Seattle, Wash. Available at: http://aats. org/annualmeeting/program-books/2015/23.cgi.

20. Hachey KJ, Hewes PD, Porter LP, Ridyard DG, Rosenkranz P, McAneny D, et al Caprini venous thromboembolism risk assessment permits selection for postdischarge prophylactic anticoagulation in patients with resectable lung cancer. $J$ Thorac Cardiovasc Surg. 2016;151:37-44.

21. Caprini JA. Risk assessment as a guide for the prevention of the many faces of venous thromboembolism. Am J Surg. 2010;199(1 Supp):s3-10.

22. Wechsler RJ, Salazar AM, Gessner AJ, Spirn PW, Shah RM, Steiner RM. CT of in situ vascular stump thrombosis after pulmonary resection for cancer. Am J Roentgenol. 2001;176:1423-5.

23. Joshi M, Farooq U, Mehrok S, Srouji N. Delayed formation of pulmonary artery stump thrombus: a case report and review of the literature. Thrombos $J$. 2009;7:7.

24. Barbetakis N, Asteriou C, Kleontas A. Post-lobectomy pulmonary artery stump thrombosis: how dangerous is it? Ann Thorac Surg. 2011;91:e44.

25. Kim SY, Seo JB, Chae EJ, Do KH, Lee JS, Song JW. Filling defect in a pulmonary artery stump on CT afer pneumonectomy: radiologic and clinical significance. Am J Roengenol. 2005;185:985-8.

26. Thomas PA, Doddoli C, Barlesi F, Reynaud-Gaubert M, Giudicelli R, Fuentes P Late pulmonary artery stump thrombosis with post-embolic pulmonary hypertension after pneumonectomy. Thorax. 2006;61:177-8.

27. Schneider L, Farrokhyar F, Schieman C, Hanna WC, Shargall Y, Finley CJ. The burden of death following discharge after lobectomy. Eur J Cardiothorac Surg. 2015;48:65-70.

28. Schneider L, Farrokhyar F, Schieman C, Shargall Y, D’Souza J, Camposilvan I, et al. Pneumonectomy: the burden of death following discharge and predictors of surgical mortality. Ann Thorac Surg. 2014;98:1976-82.

Key Words: pulmonary embolism, deep vein thrombosis, lung cancer resection, screening, prevalence 